\title{
Effects of sexual harassment on work-family enrichment: the roles of organization-based self-esteem and Polychronicity
}

\author{
Haixiao Chen ${ }^{1}$ (D) Ho Kwong Kwan ${ }^{2} \cdot$ Wei-ling Ye ${ }^{1}$
}

Accepted: 4 August 2021 / Published online: 2 September 2021

(C) The Author(s), under exclusive licence to Springer Science+Business Media, LLC, part of Springer Nature 2021

\begin{abstract}
Drawing on the work-home resources model, this study investigated the relationship between sexual harassment perceived by employees in the workplace and their workfamily enrichment. We considered the potential mediating role of employees' organization-based self-esteem and moderating role of their polychronicity. Using two-wave time-lagged data collected from 362 part-time Master of Business Administration students with full-time jobs in China, we found that perceived sexual harassment at work was negatively related to employees' work-family enrichment via reduced organization-based self-esteem. Polychronicity alleviated the negative relationship between sexual harassment and organization-based self-esteem, and the mediating effect of sexual harassment on work-family enrichment through decreased organization-based self-esteem. We discuss the theoretical and practical implications of these findings.
\end{abstract}

Keywords Sexual harassment · Polychronicity · Organization-based self-esteem · Workfamily enrichment

An earlier version of the article was presented at the 2019 Frontiers of Business Research in China International Symposium, Beijing, China.

Haixiao Chen

chenhaixiao1218@foxmail.com

Ho Kwong Kwan

weicheong2317@hotmail.com

Wei-ling Ye

ye.weiling@mail.sufe.edu.cn

1 College of Business, Shanghai University of Finance and Economics, Shanghai 200433, People's Republic of China

2 Organizational Behavior and Human Resource Management Department, China Europe International Business School (CEIBS), Shanghai 201206, People's Republic of China 
In the last few decades, research on work-family enrichment (WFE) has dramatically increased (e.g., Bhave \& Lefter, 2018; Lapierre et al., 2018). "WFE" refers to the extent to which experiences in the work domain improve quality of life in the family domain (Greenhaus \& Powell, 2006). A meta-analytic study by Lapierre et al. (2018) identified various predictors of WFE, such as social support at work, a family-friendly work culture, work autonomy, and work tenure.

Despite this fruitful empirical evidence of the antecedents of WFE, an important research gap remains regarding factors that hinder WFE. Influenced by growing academic interest in positive psychology, studies of WFE have mainly focused on the effects of positive organizational constructs on WFE (e.g., Carlson et al., 2011; Zhang et al., 2012). Theoretical and empirical explanations of how negative workplace constructs can hinder WFE are lacking (Loi et al., 2018). Although scholars have elaborated on the formation of WFE by specifying "the conditions under which work and family roles are 'allies' rather than 'enemies"' (Greenhaus \& Powell, 2006: 72), we know little about how the formation of work-family allies may be hindered. Organizations are placing increasing emphasis on employees' nonwork needs and WFE is of strategic importance to individuals' work-family balance (Kreiner et al., 2009; Zhang et al., 2012), especially during the COVID-19 pandemic, when work-family balance is particularly valued by employees (Kramer \& Kramer, 2020; Shockley et al., 2021). Research examining the impact of negative work experiences, such as discrete social stress, on WFE could generate practical guidance for organizations and individuals on alleviating this impact (e.g., Lapierre et al., 2018).

To fill this gap in the research, we focused on workplace sexual harassment, which has been identified as one of the most pervasive and costly negative workplace occurrences (Berdahl \& Raver, 2010; Willness et al., 2007). Sexual harassment is defined in this study as "unwanted sex-related behavior at work that is appraised by the recipient as offensive, exceeding her/his resources, or threatening her/his well-being" (Fitzgerald et al., 1997: 15). Research has shown that workplace sexual harassment can affect the victim's life outside work, such as their romantic relationships (Dionisi \& Barling, 2015) and family relationships (Liao et al., 2016). A recent meta-analysis reported that work overload was not significantly related to WFE (Lapierre et al., 2018), which implies that work overload, including job tension, may not be a significant mediator of the process by which WFE is hindered. However, as workplace sexual harassment has unique effects beyond the impact of job stress (Dionisi \& Barling, 2015; Schneider et al., 1997), we argue that investigating workplace sexual harassment may provide a unique explanation for hindered WFE.

To further understand the mediating mechanism underlying the relationship between workplace sexual harassment and WFE, we drew on the work-home resources (WHR) model, which regards self-esteem as an important personal resource, to account for the effects of contextual factors on WFE (e.g., Greenhaus \& Powell, 2006; ten Brummelhuis \& Bakker, 2012). The W-HR model posits that contextual work demands (e.g., emotional and mental demands) diminish positive outcomes in the family domain through the loss of personal resources (ten Brummelhuis \& Bakker, 2012). Based on the W-HR model, we attempted to determine the extent to which encountering sexual harassment at work reduces targets' organization-based self-esteem (OBSE; Pierce \& Gardner, 2004), which in turn impedes their WFE. OBSE is "the self-perceived value that individuals have of themselves as organization members 
acting within an organizational context" (Pierce et al., 1989: 625). Research has suggested that workplace sexual harassment affects employees' personal identity and self-esteem (Dionisi et al., 2012; Luhtanen \& Crocker, 1992; Wright \& Fitzgerald, 2007). Similar to other forms of interpersonal mistreatment that negatively affect employees' self-worth and self-evaluation within their organization (e.g., Frone, 2000; Lim \& Lee, 2011), workplace sexual harassment represents an attack on a core component of the self (Lim \& Cortina, 2005; Liu et al., 2014). Hence, we argue that OBSE plays a mediating role in the relationship between sexual harassment and WFE.

We also investigated the boundary conditions of the effects of workplace sexual harassment, which helped us to identify variables that can buffer the deleterious effects of workplace sexual harassment on employees' WFE. Research has indicated that victims of sexual harassment try to manage their situation (Fitzgerald \& Cortina, 2018). Some employees can maintain relatively high levels of job performance despite encountering workplace sexual harassment (O'Leary-Kelly et al., 2009). However, sexual harassment often becomes a chronic stressor and managing its effects requires long-term efforts (Quick \& McFadyen, 2017). As Fitzgerald and Cortina (2018: 223) indicated, "responding to sexual harassment [is] a process, not a single act." Sexual harassment may frequently interrupt victims' workflow, as dealing with it deprives them of time and energy. For example, research has indicated that the experience of workplace sexual harassment often disrupts victims' work tasks and leads them to withdraw from engagement in their work (Fitzgerald et al., 1997; O'Leary-Kelly et al., 2009).

Referring to the work interruption literature (e.g., Jett \& George, 2003; Pachler et al., 2018), we identified the moderating role of employee polychronicity, a personal characteristic that has been underexamined in the literature on coping with mistreatment. The construct of polychronicity describes a situation in which individuals prefer to multitask and switch attention between ongoing tasks as opposed to performing one task at a time (Bluedorn et al., 1999; Poposki \& Oswald, 2010). As more polychronic employees have been found to be more comfortable with attention switching and thus less vulnerable to the negative effects of work interruption (Pachler et al., 2018; Poposki \& Oswald, 2010), polychronicity may help alleviate the interference caused by workplace sexual harassment. Thus, we examined the potential moderating role of polychronicity in our model.

This study contributes to the literature in three ways. First, we contribute to the work-family literature by exploring the process by which WFE is hindered. By introducing workplace sexual harassment to the WFE literature, we enhance understanding of hindered WFE and build a more comprehensive and complex model of WFE. This approach responds to the call of Lapierre et al. (2018) to pay attention to the discrete forms of interpersonal mistreatment in the workplace that are associated with WFE. Second, drawing on the W-HR model, we uncover a critical intervening mechanism underlying the process by which WFE is hindered and reveal the mediating role of OBSE in the relationship workplace sexual harassment and WFE. Third, we identify a personal buffering characteristic, polychronicity, that can help explain victims' different responses to hindered WFE. The findings may have valuable practical implications for organizations seeking to alleviate the destructive effects of workplace sexual harassment. 


\section{Theoretical background and hypotheses}

\section{Conceptual background of the W-HR model}

Unlike conventional theories of work-family relationships, which focus on either the conflict process (Frone et al., 1992; Pleck, 1977) or the enrichment process (e.g., Barnett \& Hyde, 2001; Greenhaus \& Powell, 2006), the W-HR model (ten Brummelhuis \& Bakker, 2012) provides an integral and detailed theoretical framework to explain both positive and negative work-home processes. Building on the conservation of resources theory (Hobfoll, 1989, 2002), one of the most influential theories explaining how individuals react to stressors in their environment and how they are influenced by these encounters, the $\mathrm{W}-\mathrm{HR}$ model proposes that personal resources are the main mechanism that helps to determine whether the relationship between one's work role and family role is enriching or depleting. To influence the family domain, workplace contextual resources or demands must first bring about changes to one's personal resources (ten Brummelhuis \& Bakker, 2012). According to the model, depleted personal resources in the work context lead to negative outcomes in the family context (ten Brummelhuis \& Bakker, 2012)

The W-HR model also explains how conditional resources (e.g., personality) influence the relationship between workplace contextual demands/resources and family outcomes. Hobfoll (2001) pointed out that conditional resources function to promote the efficiency and effectiveness of other resources. The W-HR model divides conditional factors into two categories of resources: key resources (e.g., self-efficacy, optimism) and macro resources (e.g., cultural adaptation, high social expectations). In this study, we focus on key resources that "facilitate the selection, alteration, and implementation of other resources" (ten Brummelhuis \& Bakker, 2012: 548). The $\mathrm{W}-\mathrm{HR}$ model suggests that possessing such key resources can alleviate the negative effects of the contextual demands of an employee's work on their family outcomes and facilitate their use of other resources (ten Brummelhuis \& Bakker, 2012). For example, employees with intrinsic job motivation tend to suffer less from the effects of stressors and have more positive ways to cope with resource loss (Lyu \& Zhu, 2019; ten Brummelhuis et al., 2011). Thus, the notion of key resources extends our understanding of how people deal with stressors and why some individuals cope with stressful circumstances better than others do (ten Brummelhuis \& Bakker, 2012).

In this study, we applied the W-HR model to understand how and when workplace sexual harassment hinders WFE through OBSE. Specifically, sexual harassment as interpersonal mistreatment or a contextual work demand should lead to the depletion of an employee's OBSE (personal resource), which in turn results in reduced WFE. In addition, we argue that polychronicity is a key but under-researched individual characteristic (key resource) that can moderate the relationships among sexual harassment, OBSE, and WFE. Figure 1 illustrates the conceptual model developed and tested in our study.

\section{Sexual harassment as an antecedent of OBSE}

Considering the interpersonal nature of workplace sexual harassment, we argue that experiencing sexual harassment at work damages victims' OBSE. OBSE reflects individuals' self-perceived value and competence specifically within the workplace. 


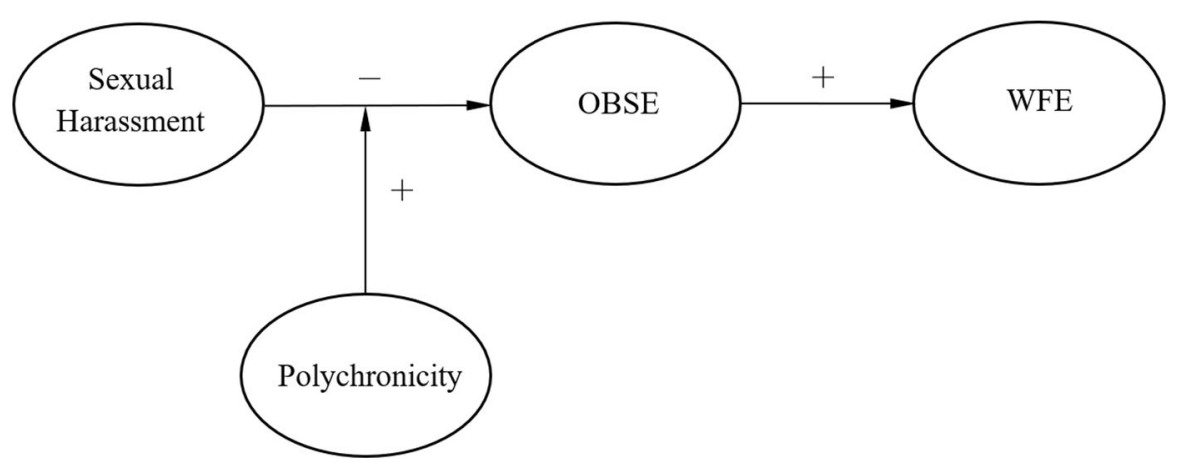

Fig. 1 The conceptual model. Notes: OBSE = Organization-based self-esteem; WFE = Work-to-family enrichment

Employees with high OBSE believe that they are important, meaningful, respected, and valuable from the perspective of their organization. Pierce and Gardner (2004) summarized three major categories of workplace situational antecedents of employees' OBSE: 1) feelings of efficacy and competence derived from personal work experience, 2) social interactions (e.g., abusive supervision) that convey to employees the extent to which they are valued and important, and 3) the environmental structure of the organization (e.g., high involvement) that signals trust in employees.

Given that successfully fulfilling one's work duties and establishing competence are important prerequisites for developing and maintaining OBSE (Pierce \& Gardner, 2004), a lack of positive work experiences may hamper employees' OBSE. Research has suggested that sexual harassment is a workplace stressor that can deplete employees' personal resources and reduce their productivity (see Willness et al., 2007 for a review). Sexual harassment also poses a threat to victims and increases their intention to withdraw from fulfilling their work duties (Fitzgerald et al., 1997). Moreover, targets may perceive themselves as victims of injustice and thus become "disillusioned and angry, not only with the harasser but also with the organization itself" (Willness et al., 2007: 135), as organizations are usually expected to protect employees from negative workplace incidents such as sexual harassment (Adams \& Bray, 1992). Such negative work experiences are likely to make employees question their value to the organization.

In addition, scholars have suggested that OBSE can "find its roots, in part, in messages of value transmitted from the organization to the employee via interpersonal relationships" (Pierce \& Gardner, 2004: 601). Research has shown that interpersonal mistreatment (e.g., abusive supervision and workplace incivility) can negatively affect employees' self-worth and positive self-evaluation within their organizations (e.g., Jian et al., 2012; Lim \& Lee, 2011). Sexual harassment is a pervasive form of interpersonal mistreatment that conveys disrespectful, demeaning, and/or derogatory information to victims (e.g., Berdahl \& Raver, 2010; Fitzgerald \& Cortina, 2018). Experiencing this type of mistreatment at work may injure employees' self-worth and self-evaluation. When employees perceive themselves to be targeted by sexual harassment, they may question their value and self-worth within the organization. For example, Hershcovis et al. (2010) regarded sexual harassment as an identity threat, leading victims to overwork to prove their worth. Parker and Griffin (2002) empirically found that perceived sexual harassment can lead to over-performance demands, defined as targets' 
"perceptions of the need to overperform to gain acceptance and recognition within the organization" (Parker \& Griffin, 2002: 196). Thus, considering these findings, we proposed the following hypothesis:

Hypothesis 1 Perceived sexual harassment is negatively related to employees' OBSE.

\section{Sexual harassment, OBSE, and WFE}

Drawing on the $\mathrm{W}-\mathrm{HR}$ model, we posited that workplace sexual harassment impedes employees' WFE through diminished OBSE. WFE arises when experiences in the work domain produce positive experiences and outcomes in the family domain (Greenhaus \& Powell, 2006). Self-esteem has been identified as an important psychological resource conducive to WFE (e.g., Greenhaus \& Powell, 2006). Recent research has shown that general self-esteem plays a mediating role in the relationship between work stressors and WFE (Tan, 2020). However, we argue that general self-esteem involves many other domains (such as community) that are unrelated to our model. Compared with general self-esteem, which represents an individual's overall evaluation of self (Bowling et al., 2010), OBSE is not only conceptually more relevant to workrelated variables (Pierce et al., 1989); it also has stronger empirical relationships with work-related variables (Bowling et al., 2010). Hence, we believe that it is more precise and relevant to use OBSE instead of general self-esteem to examine WFE (as opposed to individual experience in the general life domain).

OBSE leads to positive self-appraisals, stimulates motivation, and enhances performance, which can be cognitively crystallized and used to enhance performance in family roles, thereby increasing WFE. Specifically, as suggested by Greenhaus and Powell (2006), two enrichment paths can help explain how OBSE induces WFE and enhances individuals' family performance. The first is an instrumental path, through which resources accumulated at work are directly applied to enhance performance in family roles. OBSE reflects a positive view of self at work, which helps expand individuals' thought-action repertoires and strengthens their outward focus of attention (Fredrickson \& Branigan, 2005; Yang et al., 2018). Consequently, employees can directly use these resources to improve their performance in the family domain, such as paying close attention to family members' needs (ten Brummelhuis \& Bakker, 2012). The second is an affective path, in which positive affect generated in an employee's work role is carried over to their family role and improves their ability to fulfil family responsibilities. Research has suggested that OBSE is highly associated with positive affect (Isen \& Baron, 1991; Pierce et al., 1989), as it gives employees the energy needed to fulfil their family responsibilities and enhances their WFE (Greenhaus \& Powell, 2006; Rothbard, 2001). Recognizing that employees' feelings of self-worth in an organization can enrich their family lives through instrumental and affective paths, we hypothesized that there is a positive relationship between OBSE and WFE.

In contrast, when victims' OBSE is diminished by sexual harassment by coworkers, their WFE is likely to be impeded. Several plausible explanations may help illustrate why decreased OBSE leads to reduced WFE. First, experiencing low OBSE reduces employees' positive engagement in the work domain, which hinders the WFE process. 
Low OBSE indicates that one perceives oneself as neither valuable nor worthwhile within the organization (Pierce \& Gardner, 2004), suggesting that investing in one's work role adds little value to the organization. As a result, rather than investing their sense of self in the work domain, individuals with decreased OBSE detach their sense of self from their work, resulting in disengagement (Bowling et al., 2010). The activation of WFE depends on positive experiences in a work role that can be used to help improve performance in a family role (Greenhaus \& Powell, 2006); conversely, individuals with low OBSE minimize their investment in their work, leading to reduced WFE. Second, employees with lower OBSE are less likely to focus on using their experiences at work to enrich their family roles due to their reduced outward focus of attention. Research has indicated that self-esteem helps increase one's outward focus of attention and broadens thought-action repertoires (Yang et al., 2018). However, low self-esteem precedes self-protection motivation and narrows employees' attention spans (Crocker et al., 2003; Korman, 2001). This prevents them from paying attention to their family members and devoting effort to transferring benefits from work to family. Third, employees with low OBSE tend to experience negative moods and lack job satisfaction (Heck et al., 2005; Pierce \& Gardner, 2004). Thus, they have less energy to fulfil their family responsibilities, reducing WFE.

We argue that OBSE plays a mediating role in the relationship between perceived sexual harassment and WFE in the framework of the W-HR model (ten Brummelhuis \& Bakker, 2012). In the W-HR model, workplace sexual harassment can be characterized as a contextual work demand that requires sustained physical and/or mental effort (ten Brummelhuis \& Bakker, 2012). OBSE has been identified as a personal resource that can be depleted by contextual work demands (Hobfoll, 2002; ten Brummelhuis \& Bakker, 2012). According to the W-HR model, contextual work demands consistently deplete one's personal resources and further adversely affect one's family outcomes (ten Brummelhuis \& Bakker, 2012). We proposed the following hypothesis:

Hypothesis 2 OBSE mediates the relationship between perceived sexual harassment and WFE.

\section{The moderating role of polychronicity}

We also focused on the potential moderating effects of polychronicity, an individual difference variable. Some researchers have conceptualized polychronicity as a preference for multitasking combined with actual behavior that structures time in a polychronic way (e.g., Cotte \& Ratneshwar, 1999; Fournier et al., 2013). Others have argued that polychronicity should be understood only as a preference for multitasking (e.g., Poposki \& Oswald, 2010; Slocombe \& Bluedorn, 1999). However, to keep polychronicity conceptually and operationally distinct from multitasking performance (Poposki \& Oswald, 2010), we define polychronicity as a stable preference for engaging in two or more tasks or events simultaneously, shifting attention between ongoing tasks (Bluedorn et al., 1999; Poposki \& Oswald, 2010).

The essence of polychronicity is that individuals have different preferences regarding how they organize and structure their time (Bluedorn et al., 1999; Hall, 1959). In 
the definition of polychronicity, the word "simultaneously" implies two aspects or meanings of the concept. One is a multitasking orientation, referring to an individual's preference for dealing with two or more tasks at a time (Ofori-Dankwa \& Julian, 2001). The other is a task switching preference, referring to an individual's preference for switching between ongoing tasks rather than focusing on one task until it is finished and then shifting to another (Poposki \& Oswald, 2010).

The W-HR model posits that the deleterious effects of contextual work demands on personal resources are less likely to appear among individuals with more key resources, because such resources allow for an efficient coping style (ten Brummelhuis \& Bakker, 2012). Although polychronicity is not identified as a potential moderator in the W-HR model, we argue that it plays an important role in selecting, altering, and implementing other resources and thus should lead individuals to cope with sexual harassment more effectively (ten Brummelhuis \& Bakker, 2012). Research on multitasking has identified polychronicity as a stable resource for individuals in conditions where there are multiple contextual demands (Korabik et al., 2017). For example, a positive association has been found between polychronicity and job performance in situations that require multitasking, such as work interruption (e.g., Fournier et al., 2013). Thus, following the framework of the W-HR model, we argue that employees with higher levels of polychronicity are better able to alleviate the negative effects of sexual harassment at work on their OBSE.

Specifically, polychronicity may reduce the influence of derogatory information signaled by sexual harassment. Evidence from neurological research indicates that the human brain has evolved to perform one task at a time (Madore et al., 2020). Multitasking is positively related to memory failure and associated with an increased frequency of attention lapses (e.g., distraction), leading to poor episodic memory (König et al., 2005; Madore et al., 2020). Although people who prefer multitasking are likely to take a long time to complete tasks and make mistakes, a preference for multitasking may offer an advantage for individuals encountering workplace sexual harassment.

As sexual harassment represents a chronic stressor, coping with sexual harassment is a long-term process, not a single act (Fitzgerald \& Cortina, 2018). In terms of the complexity of coping (Cortina \& Wasti, 2005; Knapp et al., 1997), sexual harassment frequently interrupts the flow of work and requires targets to reallocate their time and switch attention between coping with sexual harassment and fulfilling work duties. Employees who experience sexual harassment are likely to feel that they are subject to over-performance demands (Hershcovis et al., 2010). A recent study showed that work interruptions have negative effects on employee well-being (Keller et al., 2020). Polychronicity enables people to fulfill their work roles in organizations when there are interruptions (Hui et al., 2010; Poposki \& Oswald, 2010). As such, employees with high levels of polychronicity may be relatively comfortable with shifting attention between coping with sexual harassment and fulfilling their work duties when they are sexually harassed. In other words, polychronicity may help them cope with the interference of sexual harassment. As successfully fulfilling one's role and establishing competence are important prerequisites for developing and maintaining OBSE (Pierce \& Gardner, 2004), the OBSE of more polychronic employees is less likely to be influenced by exposure to sexual harassment. Thus, we hypothesized that polychronicity alleviates the negative effects of sexual harassment on depleting OBSE. 
Hypothesis 3 Polychronicity moderates the negative relationship between perceived sexual harassment and OBSE, such that the relationship is weaker when polychronicity is high rather than low.

Hypotheses 1-3 state that sexual harassment at work can negatively affect a victim's WFE by depleting his or her OBSE and polychronicity can attenuate the negative effects of sexual harassment on OBSE. The W-HR model suggests that there is an integrated model in which key resources not only buffer the negative link between contextual work demands and personal resources but also moderate the whole process from the work domain to the family domain (ten Brummelhuis \& Bakker, 2012). Thus, it is reasonable to predict that polychronicity also moderates the indirect effect of sexual harassment on WFE via OBSE. That is, because the relationship between sexual harassment at work and OBSE is weaker for more polychronic employees, the indirect effect of sexual harassment at work on their WFE via OBSE is also weaker. Combining our arguments, we hypothesized a moderated mediating relationship (Edwards \& Lambert, 2007) in which more polychronic employees who experience sexual harassment may also be less likely to experience decreased WFE via reduced OBSE.

Hypothesis 4 Polychronicity moderates the mediating effect of OBSE on the relationship between perceived sexual harassment and WFE, such that the mediating effect of perceived sexual harassment on WFE through OBSE is weaker when the level of polychronicity is high rather than low.

\section{Method}

\section{Sample and procedures}

The data used in this study were collected from employees enrolled in a part-time Master of Business Administration (MBA) program at a university in Shanghai, China. We collected our data in a Chinese context, which has high levels of familism, unlike most Western contexts (Au \& Kwan, 2009). Chinese people tend to highly value the interests of their families and view family relationships as the core of their social network structures (Lau, 1981). In China, employees generally work for the sake of their families, such that the meaning of work is inherently tied to that of family (Yang et al., 2000). Recent research has shown that a desire to work for the benefit of one's family motivates employees to work hard (Zhang et al., 2020). Consequently, Chinese employees highly value enrichment from work to family, which made China an ideal context in which to test our theorized model.

With the assistance of course teachers, we randomly selected 524 MBA students to take part in our two-wave questionnaire survey. We implemented a two-week interval to prevent potential problems associated with common method bias (Doty \& Glick, 1998). We distributed questionnaires with a cover letter to our participants and they returned the completed questionnaires directly to us. The cover letter informed the participants of the confidentiality of their responses and explained that the surveys would be used for academic research purposes only. To ensure that the participants paid attention to all of the items in the questionnaires, we also conducted an attention check process. 
In the first wave, the participants were asked to report their perceptions of sexual harassment in the workplace (the independent variable), polychronicity (the potential moderator), and job stress (the control variable), and to provide demographic information, including gender, age, marital status, education, job tenure, weekly work time, income after tax, job position, and living situation (e.g., living with spouse, living with parents, or living with children). In total, 524 questionnaires were sent out and 404 completed questionnaires were returned (a response rate of $77.10 \%$ ). In the second wave, we only sent questionnaires to the 404 participants who had completed the firstwave survey. In this wave, the participants were asked to rate their OBSE (the potential mediator) and WFE (the dependent variable). The final sample contained 362 usable responses (a response rate of $69.08 \%$ ).

All our participants worked full time in a range of industries in both the public and private sectors. They averaged 9.06 years of work experience $(S D=$ 5.45 ) and $53.04 \%$ of them were female. The average age of the sample was 32.42 years $(S D=5.21)$ and $64.78 \%$ were married. More than half $(64.08 \%)$ had a Bachelor's degree and $24.03 \%$ had a Master's degree or a Ph.D. A Bachelor's degree was not a requirement for this MBA program if the applicants had suitable executive work experience. On average, our participants worked $39.88 \mathrm{~h}$ a week $(S D=18.04)$ and most of them $(72.37 \%)$ earned more than RMB60,000 per year after tax. With respect to job position, 163 $(45.03 \%)$ were frontline employees and 199 (54.97\%) were managers. Finally, $30.94 \%$ of our participants lived with their spouses, $37.57 \%$ lived with their parents, and $42.82 \%$ lived with their children.

\section{Measures}

To ensure the reliability and validity of the results, all of the constructs in this study were measured using well-established scales. As all of the key measures were applied in a Chinese setting, Chinese versions of the scales were used. Prior to the formal investigation, we conducted a pilot study to test the appropriateness of the statements and the suitability of the items in our questionnaires. Based on the results of the pilot study, the questionnaires were revised for conciseness and understandability. Unless otherwise stated, 7-point Likert-type scales ranging from 1, "strongly disagree," to 7, "strongly agree," were used to measure the key variables in both waves.

Sexual harassment A 14-item scale extracted from Fitzgerald et al.'s (1995) original 19-item Sexual Harassment Experience Questionnaire (SEQ) was used to measure sexual harassment in this study. The participants were asked to rate their perceptions of sexual harassment directed toward them by their supervisors or coworkers. Based on the pilot study and previous research (e.g., Liu et al., 2014), we removed five items from the original SEQ questionnaire that were not suitable for the context we were studying. The original scale was divided into three dimensions: gender harassment, unwanted sexual attention, and sexual coercion. The revised scale excluded sexual coercion and mainly focused on gender harassment and unwanted sexual attention. A sample item is "Touching in a way that made you feel uncomfortable." The reliability for this measure in this study was .93 . 
Polychronicity To measure polychronicity, we used a 5-item scale originally developed by Bluedorn et al. (1999) and later applied by Hui et al. (2010) in a Chinese setting. A sample item is "I like to juggle several activities at the same time." The reliability for this measure in our study was .78.

OBSE A 10-item scale developed by Pierce et al. (1989) and later applied by Hui and Lee (2000) was used to measure OBSE. Sample items are "I matter around here" and "I am an important part of this place." The reliability for this measure in our study was .94.

WFE A nine-item scale originally developed by Carlson et al. (2006) and later applied by Kwan et al. (2010) in a Chinese setting was used to measure WFE. The scale was divided into three dimensions: development, affect, and capital. A sample item is "My involvement in my work helps me to understand different viewpoints and this helps me be a better family member." The reliability for this measure in this study was .96 .

Control variables We controlled for job stress (four items; Netemeyer et al., 2005) because many studies have indicated that job stress can significantly influence WFE (e.g., Lapierre et al., 2018). In addition, because "general job stressors provide an important baseline against which the unique effects of sexual harassment can be evaluated" (Fitzgerald et al., 1997: 579), we included job stress as a control variable when examining the effects of sexual harassment on the work-family interface. A sample item is "My job tends to directly affect my health." We also controlled for a set of demographic variables (Lapierre et al., 2018). Specifically, gender (coded as 1 for male and 2 for female) was controlled because research has suggested that men and women have fundamentally different experiences of the work-family interface (Barnett \& Hyde, 2001). Age (years), education (coded as 1 for middle school or below, 2 for high school, 3 for community college, 4 for undergraduate degree, and 5 for Master's degree or above), tenure (years), weekly work hours and position (coded as 1 for frontline employee, 2 for frontline manager, 3 for middle-level manager, 4 for top manager, and 5 for director) were controlled because the life stages and human resources of the employees might have affected their WFE (Friedman \& Greenhaus, 2000). Income after tax, coded from 1 for below RMB20,000 per year to 10 for above RMB180,000 per year, was treated as a pragmatic resource that could have a substantial influence on both the work and family domains (Greenhaus \& Powell, 2006). In addition, we controlled for marital status (coded as 1 for married and 2 for not married), living with spouse, living with parents, and living with children (each coded as 1 for yes and 2 for no) to consider aspects of an individual's family situation that might influence the work-family interface (Friedman \& Greenhaus, 2000).

\section{Results}

\section{Descriptive statistics}

Table 1 presents the means, standard deviations, and correlations among the variables, as well as reliability estimates. Sexual harassment was negatively related to both OBSE 


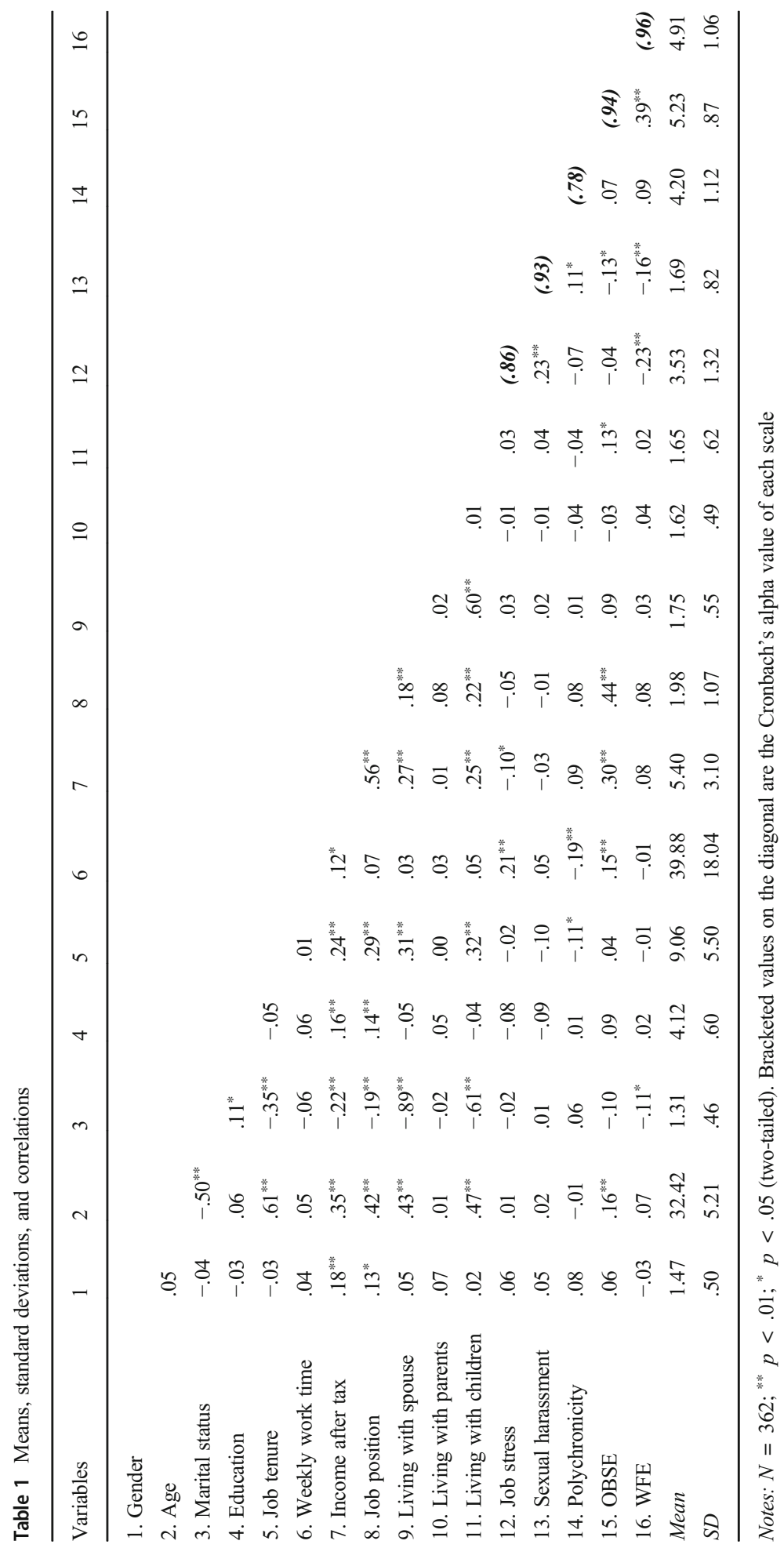


$(r=-.13, p<.05)$ and WFE $(r=-.16, p<.01)$. OBSE was positively related to WFE $(r=.39, p<.01)$. These correlation results provide preliminary support for our hypotheses.

\section{Confirmatory factor analysis}

We conducted confirmatory factor analysis (CFA) with Mplus 7.4 to estimate the convergent validity of the measurement model and assess the distinctiveness of our key variables (i.e., sexual harassment, polychronicity, OBSE, WFE, and job stress). After considering the small sample size associated with our scale items (Landis et al., 2000), we used the item parceling process suggested by Nasser and Wisenbaker (2003) to reduce the number of estimated parameters. Specifically, based on exploratory factor analysis, we created three indicators for each unidimensional construct (i.e., polychronicity, OBSE, and overall job stress) that involved more than three items (Mathieu \& Farr, 1991). We combined the items with the highest and lowest factor loadings as the first indicator, the second highest and lowest as the next indicator, and so on to create three empirically balanced parcels. In addition, we included the multidimensional constructs (i.e., sexual harassment and WFE) in the CFA as second-order factors. This item parceling method has frequently been applied to overcome the nonconvergence issue and enhance the reliability of the measurement model (e.g., Takeuchi et al., 2015). As shown in Table 2, the results indicated that the five-factor model fitted the data well, $\chi^{2}=319.75, d f=176, p<.001$, root mean square error of approximation $($ RMSEA) $=.05$, comparative fit index $(\mathrm{CFI})=.98$, Tucker Lewis index $(\mathrm{TLI})=.97$, supporting convergent validity. We then used a model comparison to examine the distinctiveness of the five key variables. Specifically, we contrasted a five-factor model with four four-factor models and one two-factor model. The results in Table 2 show that the five-factor model was superior to all of the alternative models, supporting the discriminant validity of the key measures.

To test for the problem of common method bias, we loaded all of the items of the key constructs onto a higher-order latent factor that we named the self-rating factor. The results presented in Table 2 show that the fit of the common method model $\left(\chi^{2}(189)=\right.$ $3208.26, p<.01, \mathrm{RMSEA}=.21$, TLI $=.53$, and CFI $=.48)$ was inferior to that of the measurement model $\left(\Delta \chi^{2}(\Delta d f=13)=2988.61, p<.01\right)$. Thus, common method variance was not a serious issue.

\section{Hypothesis testing}

To test our hypotheses, we conducted hierarchical multiple regression analyses. The regression results are presented in Table 3. Hypothesis 1 proposes that sexual harassment has a negative effect on WFE. Model 6 showed that sexual harassment was significantly and negatively associated with WFE $(B=-.15$; s.e. $=.07, p<.05)$, supporting Hypothesis 1.

Hypothesis 2 proposes that OBSE mediates the relationship between sexual harassment and WFE. Model 2 showed that sexual harassment was positively related to OBSE $(B=-.14 ;$ s.e. $=.05, p<.01)$. Model 7 indicated a significantly positive relationship between OBSE and WFE $(B=.54$; s.e. $=.07, p<.01)$. When both sexual harassment and OBSE were included in the model (Model 8), OBSE still significantly 


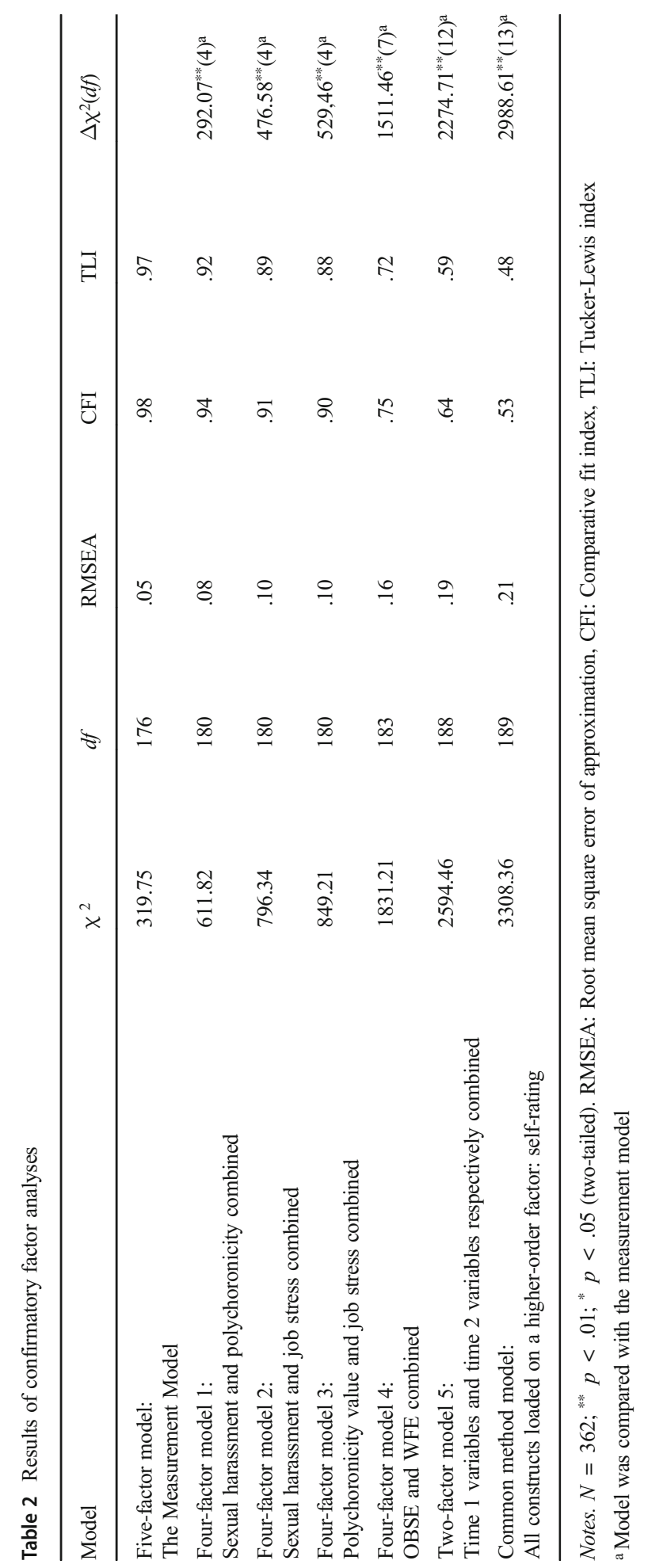




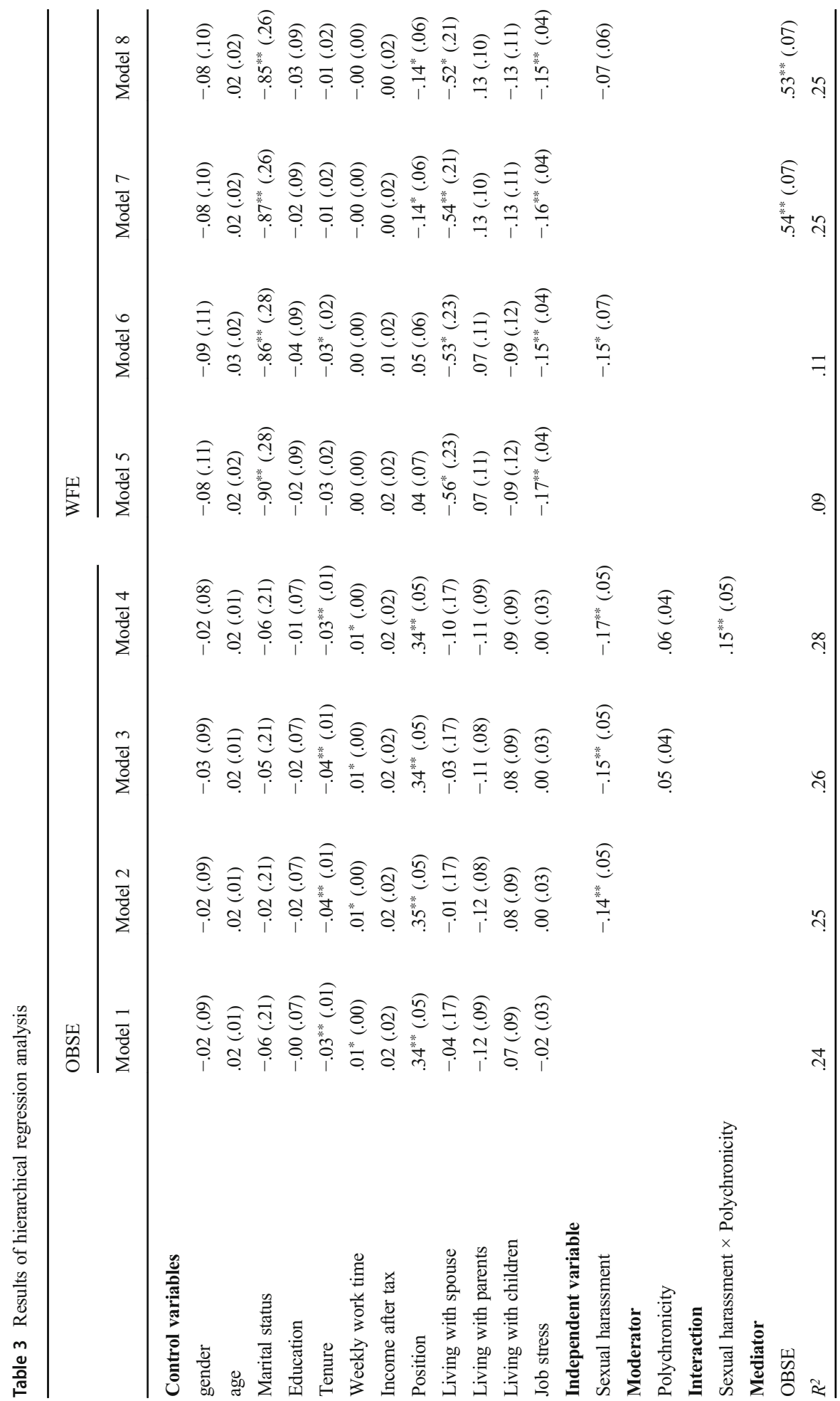




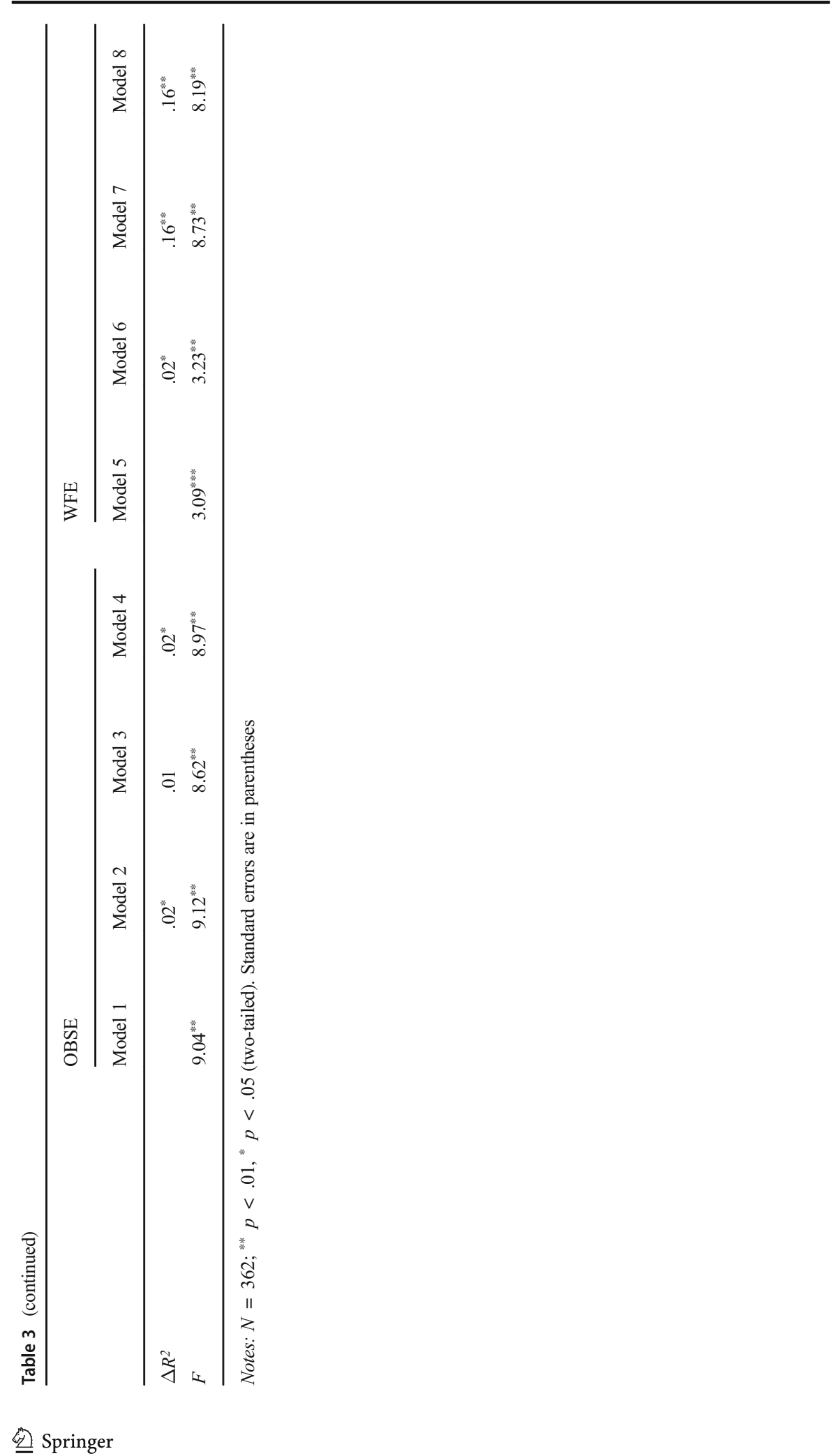


predicted WFE $(B=.53 ;$ s.e. $=.07, p<.01)$, whereas the effect of sexual harassment on WFE became nonsignificant $(B=-.07$; s.e. $=.06, N S)$. To further examine the mediating effect of OBSE, we used the Monte Carlo method, generating unbiased confidence intervals (CIs) of the indirect effect (20,000 resampling; Preacher et al., 2010). The results presented in Table 4 indicate that the indirect effect of sexual harassment on WFE via OBSE was significant $(B=-.09 ;$ s.e. $=.03 ; 95 \%$ CI $[-.16$, -.04], excluding zero). Thus, Hypothesis 2 was supported.

Hypothesis 3 proposes that polychronicity moderates the relationship between sexual harassment and OBSE. The results in Table 3 indicate that the interaction between sexual harassment and polychronicity was significantly associated with OBSE (Model 4; $B=.15 ;$ s.e. $=.05 ; p<.01$ ). To better comprehend the moderating effect of polychronicity, we conducted a simple slope analysis of its low and high levels (1 SD lower than the mean and $1 S D$ higher than the mean, respectively). According to the results shown in Fig. 2, sexual harassment was significantly and negatively related to OBSE when polychronicity was low $(B=-.33$; s.e. $=.08 ; p<.05)$, but it did not predict OBSE when polychronicity was high $(B=.00 ;$ s.e. $=.07 ; N S)$, further supporting Hypothesis 3.

Hypothesis 4 proposes a moderated mediation model. To test this hypothesis, we generated unbiased CIs of the conditional indirect effect by conducting a bootstrappingbased analytic process via Mplus 7.4 (Preacher et al., 2010). As shown in Table 4, the indirect relationship from sexual harassment to WFE through OBSE was weaker when polychronicity was high $(+1 S D ; B=-.00$, s.e. $=.04,95 \%$ CI $[-.06, .09]$, including zero) than when polychronicity was low $(-1 S D ; B=-.17$, s.e. $=.05,95 \%$ CI $[-.29$, $-.08]$, excluding zero). The difference between the two levels was significant $(\Delta B=$ .17 , s.e. $=.07,95 \%$ CI [.06, .33], excluding zero). Thus, Hypothesis 4 was supported.

\section{Discussion}

In this study, we examined the influence of perceived sexual harassment on employees' WFE. Applying the W-HR model (ten Brummelhuis \& Bakker, 2012), we found that employees' perceptions of sexual harassment negatively affected their WFE through diminished OBSE. Employees' polychronicity played a key role in attenuating this indirect negative relationship.

Table 4 Result of conditional indirect effect of polychronicity

Sexual harassment $(\mathrm{X}) \rightarrow$ OBSE $(\mathrm{M}) \rightarrow \mathrm{WFE}(\mathrm{Y})$

\begin{tabular}{lccc}
\hline Relationships & $B$ & s.e. & $95 \%$ bias-correct CI \\
\hline Mean level & -.09 & .03 & {$[-.16,-.04]$} \\
Conditional indirect effect: & & & \\
Low level $(-1 S D)$ & -.17 & .05 & {$[-.29,-.08]$} \\
High level $(+1 S D)$ & -.00 & .04 & {$[-.06, .09]$} \\
Difference & .17 & .07 & {$[.06, .33]$} \\
\hline
\end{tabular}

Notes: $N=362 ;$ Bootstrapping $=10,000$ 


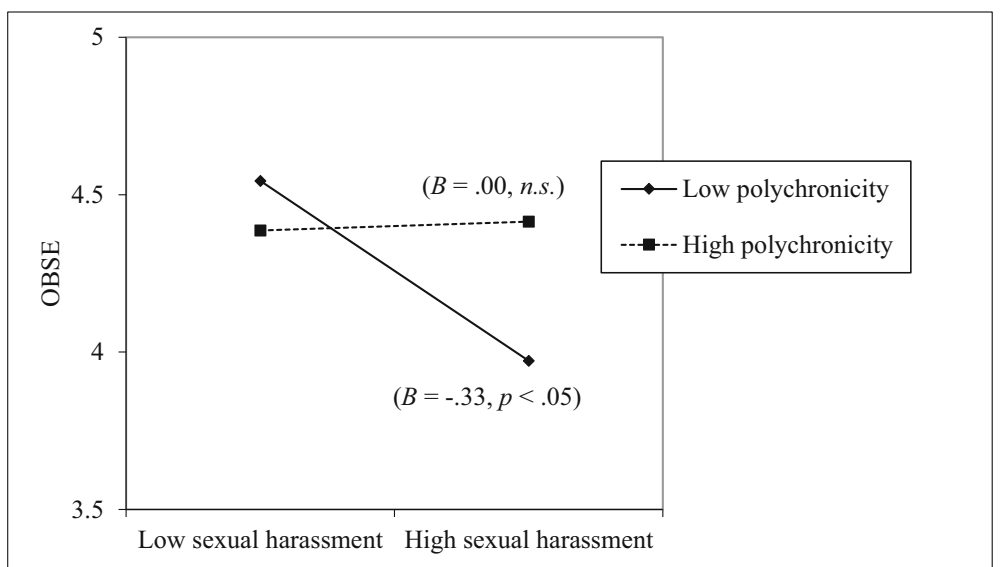

Fig. 2 The moderating effect of polychronicity on the relationship between sexual harassment and OBSE

\section{Theoretical implications}

Our findings contribute to the literature in three ways. First, they enhance understanding of the process by which WFE is hindered by theoretically framing and empirically verifying a conceptual model that integrates workplace interpersonal mistreatment (i.e., sexual harassment) with WFE. Studies have shown that access to work-specific resources provides employees with personal resources that facilitate WFE (e.g., Siu et al., 2010; Wayne et al., 2007) and that workplace sexual harassment increases victims' work-family conflict (WFC) (Xin et al., 2018), defined as inter-role conflict between work and family roles (Greenhaus \& Beutell, 1985). However, how and when the WFE process is hindered by negative workplace constructs remain underexplored. WFE has been recognized as distinct from WFC (e.g., Frone, 2003; Witt \& Carlson, 2006); they are not "parallel concepts" (Gareis et al., 2009: 697). A low level of WFE does not imply a high level of WFC. As indicated by Powell and Greenhaus (2006), the opposite of enrichment is a lack of enrichment, not necessarily conflict. The findings of the WFC literature do not necessarily help to explain what hinders WFE (e.g., Gareis et al., 2009; McNall et al., 2010). Thus, it is important to investigate the process by which WFE is hindered. Our results demonstrate for the first time that the perception of sexual harassment at work can impede the effectiveness of employees' WFE beyond the generalized job stress that employees experience in the workplace (Schneider et al., 1997). Moreover, our study responds to the call of Lapierre et al. (2018) to pay attention to how harassment relates to WFE. We encourage future research to go beyond the positive antecedents of WFE to investigate negative work factors that may impede employees' WFE.

Second, drawing on the W-HR model (ten Brummelhuis \& Bakker, 2012), we contribute to understanding of hindered WFE process by revealing that OBSE mediates the relationship between perceived sexual harassment at work and WFE. To the best of our knowledge, this study offers the first empirical examination of the loss spiral from contextual work demands to WFE. Studies have shown that contextual demands (e.g., job stressors and family stressors) are likely to show stronger relationships with conflict than contextual resources (e.g., social support and job autonomy) do (Michel et al., 
2011). For example, WFC processes have often been understood from the perspectives of emotional work and role stressors (Michel et al., 2011; Wang \& Shi, 2020). Studies have found that WFC can be activated by family stressors (e.g., family ostracism and incivility), mainly through the experience of emotional exhaustion (e.g., Sharma \& Mishra, 2021; Ye et al., 2021). Xin et al. (2018) found that the relationship between workplace sexual harassment and victims' WFC was explained by increased job tension. However, as WFE and WFC involve distinct processes (e.g., Lapierre et al., 2018; Powell \& Greenhaus, 2006), our findings enhance understanding of the process by which WFE is hindered by uncovering an unexplored mechanism underlying the relationship between contextual demands (e.g., sexual harassment) and WFE. We found that sexual harassment perceived by employees injured their OBSE, which in turn weakened their WFE. In other words, OBSE could be a crucial psychological resource that is key to the loss spiral (ten Brummelhuis \& Bakker, 2012). The findings of this study may lay a foundation for future research that further advances understanding of the process by which WFE is hindered.

Finally, this study highlights the moderating effects of polychronicity and provides important insights into how individual differences might influence the link between discrete forms of workplace interpersonal mistreatment and WFE. Given that workplace interpersonal mistreatment often becomes a chronic stressor and occupies targets' time and attention (e.g., Fitzgerald \& Cortina, 2018; Rospenda et al., 2000), identifying the buffering role of polychronicity provides important insights into how individual differences help to alleviate the disturbance caused by workplace interpersonal mistreatment. While knowledge of polychronicity has accumulated in the domains of multitasking and time management (e.g., Fournier et al., 2013; Hecht \& Allen, 2005), it is not clear whether more polychronic employees can more efficiently cope with workplace interpersonal mistreatment. By introducing polychronicity to the mistreatment coping literature, we begin to fill this research gap. Specifically, we extend the concept of polychronicity to examine the effects of workplace sexual harassment. Our results demonstrate that polychronicity is a personal characteristic that helps to prevent sexual harassment from undermining victims' perceived self-worth at work. In addition, we answer the call of ten Brummelhuis and Bakker (2012) to find stable moderators that affect the worknon-work relationship. We suggest that polychronicity is an efficient coping characteristic that keeps sexual harassment from interfering with employees' WFE. Our findings strongly support our hypotheses regarding how the functions of polychronicity mitigate the negative effects of workplace sexual harassment on WFE through OBSE. We encourage empirical studies to continue exploring the moderating effects that other individual differences may have on the relationship between workplace mistreatment and WFE.

\section{Limitations and future directions}

This study has three limitations that should be noted. First, we relied on self-reporting to collect our data, which might have increased the likelihood of common method variance (Doty \& Glick, 1998). However, we collected data at two time points to alleviate the influence of this problem. In addition, the measured perceptions (i.e., perceived sexual harassment, OBSE, and WFE) are relatively subjective and difficult for others to assess (Zhang et al., 2012). From this perspective, the use of self-reporting measures was acceptable. Nevertheless, a longitudinal design with multiple sources (e.g., supervisor, spouse) could be used in the future to test our model. 
Second, the nature of our research design (i.e., a time-lagged survey) prevents us from drawing conclusions about causality. Although our research design was better suited than a cross-sectional design to exploring causal relationships (Doty \& Glick, 1998), causality could not be confirmed. The W-HR model provides theoretical support for our hypothesis development. However, it is possible that employees with lower OBSE are more likely to perceive themselves as targets of sexual harassment. Future research should use an experimental design to confirm the causality implied by our findings.

Finally, Fitzgerald et al. (1995) categorized three broad dimensions of sexual harassment in their Sexual Experience Questionnaire: gender harassment, unwanted sexual attention, and sexual coercion. However, in this study, we only measured gender harassment and unwanted sexual attention. Because most of the victims reported a relatively high frequency of gender-related harassment and unwanted sexual attention (Fitzgerald \& Cortina, 2018), it was appropriate to assess the participants' experience of sexual harassment using the former two situation-specific dimensions. Nevertheless, the sexual coercion dimension, reflecting a low-frequency but high-intensity experience (Sojo et al., 2016), should not be neglected. Future research could examine sexual coercion in the context of the work-family interface and explore the effect of this situation-specific type of sexual harassment on WFE.

\section{Practical implications}

Despite these limitations, our empirical findings have notable managerial implications, especially for organizations facing sexual harassment problems. First, we suggest preventive solutions for workplace sexual harassment in Asian organizations (Fitzgerald \& Cortina, 2018; Willness et al., 2007). Specifically, as Asian cultures place greater value on collectivism than Western cultures do (Ling \& Powell, 2001), the organizational climate or norms in Asian organizations tend to have more regulative power over employees' workplace activities. As a climate of sexual harassment in organizations (i.e., the shared perception that sexual harassment is informally permitted or even supported in an organization; Raver \& Gelfand, 2005) has been viewed as the strongest predictor of sexual harassment at work (Fitzgerald et al., 1995; Welsh, 1999), we suggest that organizations should establish corporate codes of ethics and sexual harassment policies to demonstrate their refusal to tolerate workplace sexual harassment. Through sexual harassment policies, organizations can create shared perceptions of clear punishments for perpetrators of sexual harassment and thus create an organizational climate that helps to restrain further occurrences of sexual harassment (Willness et al., 2007). In addition, organizations should create a system that enables employees to anonymously report harassment. As Fitzgerald and Cortina (2018) noted, the most critical factor leading sexual harassment victims and bystanders to suffer in silence is fear of retaliation. Research has indicated that people in a culture with high power distance may be more likely to take selfregulative approaches and choose an avoidance approach after being sexually harassed (Cortina \& Wasti, 2005). Thus, to prevent future instances of harassment, organizations should make efforts to protect those who have witnessed or experienced sexual harassment.

Second, as our findings reveal that sexual harassment undermines employees' OBSE, we suggest that corresponding remedial solutions could be adopted by organizations to alleviate the damage caused by workplace sexual harassment. When workplace sexual harassment has occurred, organizations should create a favorable work environment to uphold employees' perceived self-worth at work (Bowling et al., 2010). 
Specifically, focusing on manipulating the organization's structure and relational support would be helpful (Bowling et al., 2010; Pierce \& Gardner, 2004). For example, an organization could construct a high-involvement social structure to increase employees' likelihood of experiencing success at work and thereby enhance their OBSE (Pierce \& Gardner, 2004). Relational support from supervisors and coworkers also plays an important role in eliciting employees' OBSE (Bowling et al., 2010). Organizations could provide training that emphasizes the importance of relational support and teaches employees how to be supportive at work.

Third, organizations could consider tackling the destructive effects of sexual harassment by promoting polychronic values. Various methods could be used to encourage employees to engage in multitasking. For example, research has indicated that a flat and flexible organization structure that allows workers to expand their capabilities and to develop multiple skills for multiple assignments may nurture employees' polychronicity (Lindbeck \& Snower, 2000). Another approach is intentionally providing opportunities for multitasking. Scholars have suggested that being guided or required to work in a multitasking way leads to the development of polychronicity (e.g., Conte et al., 1999; König \& Waller, 2010). However, polychronicity has its own flaws. Rather than report their encounters, polychronic employees may attempt to selfregulate their experience of sexual harassment by switching their attention between tasks (Poposki \& Oswald, 2010). Sexual harassers may regard this as weakness and feel encouraged to persistently harass their victims. Thus, polychronicity may delay the resolution of sexual harassment and increase occurrences of sexual harassment at work in the long term. When dealing with sexual harassment issues, organizations and managers should focus on reducing sexual harassment pursuant to our recommended preventive solutions (Fitzgerald \& Cortina, 2018).

\section{Conclusion}

Based on the W-HR model, this study demonstrates that the negative relationship between sexual harassment at work and WFE can be explained by employees' diminished OBSE. The direct negative effect of sexual harassment on OBSE and its indirect hindering effect on WFE through OBSE can be alleviated by polychronicity. Our findings provide a springboard for future investigations of harassment constructs and the underlying mechanisms that hinder WFE.

Funding This study was funded by the National Natural Science Foundation of China (grant numbers 71572103, 71672108).

\section{References}

Adams, A., \& Bray, F. 1992. Holding out against workplace harassment and bullying. Personnel Management, 24: 48-52.

Au, K., \& Kwan, H. K. 2009. Start-up capital and Chinese entrepreneurs: The role of family. Entrepreneurship: Theory and Practice, 33: 889-908.

Barnett, R. C., \& Hyde, J. S. 2001. Women, men, work, and family. American Psychologist, 56(10): 781-796. 
Berdahl, J. L., \& Raver, J. L. 2010. Sexual harassment. In S. Zedeck (Ed.). Handbook of industrial/ organizational psychology: 641-669. Washington, DC: American Psychological Association.

Bhave, D., \& Lefter, A. M. 2018. The other side: Occupational interactional requirements and work-home enrichment. Academy of Management Journal, 61(1): 139-164.

Bluedorn, A. C., Kalliath, T. J., Strube, M. J., \& Martin, G. D. 1999. Polychronicity and the inventory of polychronic values (IPV). Journal of Managerial Psychology, 14(3/4): 205-231.

Bowling, N. A., Eschleman, K. J., Wang, Q., Krikendall, C., \& Alarcon, G. 2010. A meta-analysis of the predictors and consequences of organization-based self-esteem. Journal of Occupational and Organizational Psychology, 83(3): 601-626.

Carlson, D. S., Ferguson, M., Kacmar, K. M., Grzywacz, J. G., \& Whitten, D. 2011. Pay it forward: The positive crossover effects of supervisor work-family enrichment. Journal of Management, 37(3): 770789.

Carlson, D. S., Kacmar, K. M., Wayne, J. H., \& Grzywacz, J. G. 2006. Measuring the positive side of the work-family interface: Development and validation of a work-family enrichment scale. Journal of Vocational Behaviour, 68(1): 131-164.

Conte, J. M., Rizzuto, T. E., \& Steiner, D. D. 1999. A construct-oriented analysis of individual-level polychronicity. Journal of Managerial Psychology, 14(3/4): 269-288.

Cortina, L. M., \& Wasti, S. A. 2005. Profiles in coping: Responses to sexual harassment across persons, organizations, and cultures. Journal of Applied Psychology, 90(1): 182-192.

Cotte, J., \& Ratneshwar, S. 1999. Juggling and hopping: What does it mean to work polychronically? Journal of Managerial Psychology, 14(3/4): 184-204.

Crocker, J., Karpinski, A., Quinn, D. M., \& Chase, S. K. 2003. When grades determine self-worth: Consequences of contingent self-worth for male and female engineering and psychology majors. Journal of Personality and Social Psychology, 85(3): 507-516.

Dionisi, A. M., \& Barling, J. 2015. Spillover and crossover of sex-based harassment from work to home: Supervisor gender harassment affects romantic relationship functioning via targets' anger. Journal of Organizational Behaviour, 36(2): 196-215.

Dionisi, A. M., Barling, J., \& Dupré, K. E. 2012. Revisiting the comparative outcomes of workplace aggression and sexual harassment. Journal of Occupational Health Psychology, 17(4): 398-408.

Doty, D. H., \& Glick, W. H. 1998. Common methods bias: Does common methods variance really bias results? Organizational Research Methods, 1(4): 374-406.

Edwards, J. R., \& Lambert, L. S. 2007. Methods for integrating moderation and mediation: A general analytical framework using moderated path analysis. Psychological Methods, 12(1): 1-22.

Fitzgerald, L. F., \& Cortina, L. M. 2018. Sexual harassment in work organizations: A view from the 21st century. In C. B. Travis, J. W. White, A. Rutherford, W. S. Williams, S. L. Cook, \& K. F. Wyche (Eds.). APA handbook of the psychology of women: Perspectives on women's private and public lives: 215-234. Washington, DC, US: American Psychological Association.

Fitzgerald, L. F., Gelfand, M. J., \& Drasgow, F. 1995. Measuring sexual harassment: Theoretical and psychometric advances. Basic and Applied Social Psychology, 17(4): 425-445.

Fitzgerald, L. F., Swan, S., \& Magley, V. J. 1997. But was it really sexual harassment? Legal, behavioural, and psychological definitions of the workplace victimization of women. In W. O'Donohue (Ed.). Sexual harassment: Theory, research, and treatment: 5-28. Boston: Allyn \& Bacon.

Fournier, C., Weeks, W. A., Blocker, C. P., \& Chonko, L. B. 2013. Polychronicity and scheduling's role in reducing role stress and enhancing sales performance. Journal of Personal Selling and Sales Management, 33(2): 197-209.

Fredrickson, B. L., \& Branigan, C. A. 2005. Positive emotions broaden the scope of attention and thoughtaction repertoires. Cognition \& Emotion, 19(3): 313-332.

Friedman, S., \& Greenhaus, J. 2000. Work and family-Allies or enemies? New York:Oxford University Press.

Frone, M. R. 2000. Interpersonal conflict at work and psychological outcomes: Testing a model among young workers. Journal of Occupational Health Psychology, 5(2): 246-255.

Frone, M. R. 2003. Work-family balance. In J. C. Quick, \& L. E. Tetrick (Eds.). Handbook of occupational health psychology: 143-162. Washington, DC: American Psychological Association.

Frone, M. R., Russell, M., \& Cooper, M. L. 1992. Antecedents and outcomes of work-family conflict: Testing a model of the work-family interface. Journal of Applied Psychology, 77(1): 65-78.

Gareis, K. C., Barnett, R. C., Ertel, K. A., \& Berkman, L. F. 2009. Work-family enrichment and conflict: Additive effects, buffering, or balance? Journal of Marriage and Family, 71(3): 696-707.

Greenhaus, J. H., \& Beutell, N. J. 1985. Sources of conflict between work and family roles. Academy of Management Review, 10(1): 76-88. 
Greenhaus, J. H., \& Powell, G. N. 2006. When work and family are allies: A theory of work-family enrichment. Academy of Management Review, 31(1): 72-92.

Hall, E. T. 1959. The silent language. Garden City:Doubleday.

Hecht, T. D., \& Allen, N. J. 2005. Exploring links between polychronicity and well-being from the perspective of person-job fit: Does it matter if you prefer to do only one thing at a time? Organizational Behaviour and Human Decision Processes, 98(2): 155-178.

Heck, A. K., Bedeian, A. G., \& Day, D. V. 2005. Mountains out of molehills? Tests of the mediating effects of self-esteem in predicting work place complaining. Journal of Applied Social Psychology, 35(11): 22622289.

Hershcovis, M. S., Parker, S. K., \& Reich, T. C. 2010. The moderating effect of equal opportunity support and confidence in grievance procedures on sexual harassment from different perpetrators. Journal of Business Ethics, 92(3): 415-432.

Hobfoll, S. E. 1989. Conservation of resources: A new attempt at conceptualizing stress. American Psychologist, 44(3): 513-524.

Hobfoll, S. E. 2001. The influence of culture, community, and the nested-self in the stress process: Advancing conservation of resources theory. Applied Psychology: An International Review, 50(3): 337-421.

Hobfoll, S. E. 2002. Social and psychological resources and adaptation. Review of General Psychology, 6(4): 307-324.

Hui, C., \& Lee, C. 2000. Moderating effects of organization-based self-esteem on organizational uncertainty: Employee response relationships. Journal of Management, 26(2): 215-232.

Hui, C., Lee, C., \& Niu, X. 2010. The moderating effects of polychronicity and achievement striving on the relationship between task variety and organization-based self-esteem of mid-level managers in China. Human Relations, 63: 1395-1416.

Isen, A. M., \& Baron, R. A. 1991. Positive affect as a factor in organizational behaviour. Research in Organizational Behaviour, 13: 1-53.

Jett, Q. R., \& George, J. M. 2003. Work interrupted: A closer look at the role of interruptions in organizational life. Academy of Management Review, 28(3): 494-507.

Jian, Z. Q., Kwan, H. K., Qiu, Q., Liu, Z. Q., \& Yim, H. K. F. 2012. Abusive supervision and frontline employees' service performance. Service Industries Journal, 32(5): 683-698.

Keller, A. C., Meier, L. L., Elfering, A., \& Semmer, N. K. 2020. Please wait until I am done! Longitudinal effects of work interruptions on employee well-being. Work \& Stress, 34(2): 148-167.

Knapp, D. E., Faley, R. H., Ekeberg, S. E., \& Dubois, C. L. 1997. Determinants of target responses to sexual harassment: A conceptual framework. Academy of Management Review, 22(3): 687-729.

König, C. J., Buhner, M., \& Murling, G. 2005. Working memory, fluid intelligence, and attention are predictors of multitasking performance, but polychronicity and extraversion are not. Human Performance, 18(3): 243-266.

König, C. J., \& Waller, M. J. 2010. Time for reflection: A critical examination of polychronicity. Human Performance, 23(2): 173-190.

Korabik, K., Rhijn, T., Ayman, R., Lero, D. S., \& Hammer, L. B. 2017. Gender, polychronicity, and the work-family interface: Is a preference for multitasking beneficial? Community, Work \& Family, 20(3): 307-326.

Korman, A. K. 2001. Self-enhancement and self-protection: Toward a theory of work motivation. In M. Erez, U. Kleinbeck, \& H. Thierry (Eds.). Work motivation in the context of a globalizing economy: 121-130. Mahwah: Lawrence Erlbaum Associates, Inc..

Kramer, A., \& Kramer, K. Z. 2020. The potential impact of the Covid-19 pandemic on occupational status, work from home, and occupational mobility. Journal of Vocational Behavior, 119: 103442.

Kreiner, G. E., Hollensbe, E. C., \& Sheep, M. L. 2009. Balancing borders and bridges: Negotiating the workhome interface via boundary work tactics. Academy of Management Journal, 52(4): 704-730.

Kwan, H. K., Mao, Y., \& Zhang, H. 2010. The impact of role modelling on protégés' personal learning and work-to-family enrichment. Journal of Vocational Behaviour, 77(2): 313-322.

Landis, R. S., Beal, D. J., \& Tesluk, P. E. 2000. A comparison of approaches to forming composite measures in structural equation models. Organizational Research Methods, 3(2): 186-207.

Lapierre, L. M., Li, Y., Kwan, H. K., Greenhaus, J. H., DiRenzo, M. S., \& Shao, P. 2018. A meta-analysis of the antecedents of work-family enrichment. Journal of Organizational Behaviour, 39(4): 385-401.

Lau, S. K. 1981. Utilitarian Familism. In A. Y. C. King, \& R. P. L. Lee (Eds.). Social life and development in Hong Kong: 195-216. Hong Kong: The Chinse University Press.

Liao, Y., Liu, X.-Y., Kwan, H. K., \& Tian, Q. 2016. Effects of sexual harassment on employees' family undermining: Social cognitive and behavioral plasticity perspectives. Asia Pacific Journal of Management, 33(4): 959-979. 
Lim, S., \& Cortina, L. M. 2005. Interpersonal mistreatment in the workplace: The interface and impact of general incivility and sexual harassment. Journal of Applied Psychology, 90(3): 483-496.

Lim, S., \& Lee, A. 2011. Work and nonwork outcomes of workplace incivility: Does family support help? Journal of Occupational Health Psychology, 16(1): 95-111.

Lindbeck, A., \& Snower, D. J. 2000. Multitask learning and the reorganization of work: From Tayloristic to holistic organization. Journal of Labor Economics, 18(3): 353-376.

Ling, Y., \& Powell, G. N. 2001. Work-family conflict in contemporary China beyond an American based model. International Journal of Cross Cultural Management, 1(3): 357-373.

Liu, X.-Y., Kwan, H. K., \& Chiu, R. K. 2014. Customer sexual harassment and frontline employees' service performance in China. Human Relations, 67(3): 333-356.

Loi, R., Xu, A. J., Chow, C. W. C., \& Kwok, J. M. L. 2018. Customer misbehaviour and store managers' work-to-family enrichment: The moderated mediation effect of work meaningfulness and organizational affective commitment. Human Resource Management, 57(5): 1039-1048.

Luhtanen, R., \& Crocker, J. 1992. A collective self-esteem scale: Self-evaluation of one's social identity. Personality and Social Psychology Bulletin, 18(3): 302-318.

Lyu, Y., \& Zhu, H. 2019. The predictive effects of workplace ostracism on employee attitudes: A job embeddedness perspective. Journal of Business Ethics, 158(4): 1083-1095.

Madore, K. P., Khazenzon, A. M., Backes, C. W., Jiang, J., Uncapher, M. R., Norcia, A. M., \& Wagner, A. D. 2020. Memory failure predicted by attention lapsing and media multitasking. Nature, 587(7832): 87-91.

Mathieu, J. E., \& Farr, J. L. 1991. Further evidence for the discriminant validity of measures of organizational commitment, job involvement, and job satisfaction. Journal of Applied Psychology, 76(1): 127-133.

McNall, L. A., Nicklin, J. M., \& Masuda, A. D. 2010. A meta-analytic review of the consequences associated with work-family enrichment. Journal of Business and Psychology, 25(3): 381-396.

Michel, J. S., Kotrba, L. M., Mitchelson, J. K., Clark, M. A., \& Baltes, B. B. 2011. Antecedents of workfamily conflict: A meta-analytic review. Journal of Organizational Behavior, 32(5): 689-725.

Nasser, F., \& Wisenbaker, J. 2003. A Monte Carlo study investigating the impact of item parcelling on measures of fit in confirmatory factor analysis. Educational and Psychological Measurement, 63(5): 729757.

Netemeyer, R. G., Maxham III, J. G., \& Pullig, C. 2005. Conflicts in the work-family interface: Links to job stress, customer service employee performance, and customer purchase intent. Journal of Marketing, 69(2): 130-143.

Ofori-Dankwa, J., \& Julian, S. D. 2001. Complexifying organizational theory: Illustrations using time research. Academy of Management Review, 26(3): 415-430.

O’Leary-Kelly, A. M., Bowes-Sperry, L., Bates, C. A., \& Lean, E. R. 2009. Sexual harassment at work: A decade (plus) of progress. Journal of Management, 35(3): 503-536.

Pachler, D., Kuonath, A., Specht, J., Kennecke, S., Agthe, M., \& Frey, D. 2018. Workflow interruptions and employee work outcomes: The moderating role of polychronicity. Journal of Occupational Health Psychology, 23(3): 417-427.

Parker, S. K., \& Griffin, M. A. 2002. What is so bad about a little name-calling? Negative consequences of gender harassment for overperformance demands and distress. Journal of Occupational Health Psychology, 7(3): 195-210.

Pierce, J. L., \& Gardner, D. G. 2004. Self-esteem within the work and organizational context: A review of the organization-based self-esteem literature. Journal of Management, 30(5): 591-622.

Pierce, J. L., Gardner, D. G., Cummings, L. L., \& Dunham, R. B. 1989. Organization-based self-esteem: Construct definition, measurement, and validation. Academy of Management Journal, 32: 622-648.

Pleck, J. H. 1977. The work-family role system. Social Problems, 24(4): 417-427.

Poposki, E. M., \& Oswald, F. L. 2010. The multitasking preference inventory: Toward an improved measure of individual differences in polychronicity. Human Performance, 23(3): 247-264.

Powell, G. N., \& Greenhaus, J. H. 2006. Is the opposite of positive negative? Untangling the complex relationship between work-family enrichment and conflict. Career Development International, 11(7): 650-659.

Preacher, K. J., Zyphur, M. J., \& Zhang, Z. 2010. A general multilevel SEM framework for assessing multilevel mediation. Psychological Methods, 15(3): 209-233.

Quick, J. C., \& McFadyen, M. A. 2017. Sexual harassment: Have we made any progress? Journal of Occupational Health Psychology, 22(3): 286-298. 
Raver, J. L., \& Gelfand, M. J. 2005. Beyond the individual victim: Linking sexual harassment, team processes, and team performance. Academy of Management Journal, 48(3): 387-400.

Rospenda, K. M., Richman, J. A., Wislar, J. S., \& Flaherty, J. A. 2000. Chronicity of sexual harassment and generalized work-place abuse: Effects on drinking outcomes. Addiction, 95(12): 1805-1820.

Rothbard, N. 2001. Enriching or depleting? The dynamics of engagement in work and family roles. Administrative Science Quarterly, 46(4): 655-684.

Schneider, K. T., Swan, S., \& Fitzgerald, L. F. 1997. Job-related and psychological effects of sexual harassment in the workplace: Empirical evidence from two organizations. Journal of Applied Psychology, 82(3): 401-415.

Sharma, D., \& Mishra, M. 2021. Family incivility and instigated workplace incivility: How and when does rudeness spill over from family to work? Asia Pacific journal of management, 1-29.

Shockley, K. M., Clark, M. A., Dodd, H., \& King, E. B. 2021. Work-family strategies during COVID-19: Examining gender dynamics among dual-earner couples with young children. Journal of Applied Psychology, 106(1): 15-28.

Siu, O. L., Lu, J. F., Brough, P., Lu, C. Q., Bakker, A. B., Kalliath, T., O’Driscoll, M. P., Phillips, D. R., Chen, W.-Q., \& Lo, D. 2010. Role resources and work-family enrichment: The role of work engagement. Journal of Vocational Behaviour, 77(3): 470-480.

Slocombe, T. E., \& Bluedorn, A. C. 1999. Organizational behaviour implications of the congruence between preferred polychronicity and experienced work-unit polychronicity. Journal of Organizational Behaviour, 20(1): 75-99.

Sojo, V. E., Wood, R. E., \& Genat, A. E. 2016. Harmful workplace experiences and women's occupational well-being: A meta-analysis. Psychology of Women Quarterly, 40(1): 10-40.

Takeuchi, R., Bolino, M. C., \& Lin, C. C. 2015. Too many motives? The interactive effects of multiple motives on organizational citizenship behaviour. Journal of Applied Psychology, 100(4): 1239-1248.

Tan, J. M. 2020. Could stressors at work enrich family? A conservation of resources theory perspective. Doctoral dissertation, University of Macau, Macau, China.

ten Brummelhuis, L. L., \& Bakker, A. B. 2012. A resource perspective on the work-home interface: The work-home resources model. American Psychologist, 67(7): 545-556.

ten Brummelhuis, L. L., ter Hoeven, C. L., Bakker, A. B., \& Peper, B. 2011. Breaking through the loss cycle of burnout: The role of motivation. Journal of Occupational and Organizational Psychology, 84(2): 268287.

Wang, F., \& Shi, W. 2020. The effect of work-leisure conflict on front-line employees' work engagement: A cross-level study from the emotional perspective. Asia Pacific Journal of Management, 1-23.

Wayne, J. H., Grzywacz, J. G., Carlson, D. S., \& Kacmar, K. 2007. Work-family facilitation: A theoretical explanation and model of primary antecedents and consequences. Human Resource Management Review, 17(1): 63-76.

Welsh, S. 1999. Gender and sexual harassment. Annual Review of Sociology, 25(1): 169-190.

Willness, C. R., Steel, P., \& Lee, K. 2007. A meta-analysis of the antecedents and consequences of workplace sexual harassment. Personnel Psychology, 60(1): 127-162.

Witt, L. A., \& Carlson, D. S. 2006. The work-family interface and job performance: Moderating effects of conscientiousness and perceived organizational support. Journal of Occupational Health Psychology, 11(4): 343-357.

Wright, C. V., \& Fitzgerald, L. F. 2007. Angry and afraid: Women's appraisal of sexual harassment during litigation. Psychology of Women Quarterly, 31(1): 73-84.

Xin, J., Chen, S., Kwan, H. K., Chiu, R. K., \& Yim, F. H.-K. 2018. Work-family spillover and crossover effects of sexual harassment: The moderating role of work-home segmentation preference. Journal of Business Ethics, 147(3): 619-629.

Yang, N., Chen, C. C., Choi, J., \& Zou, Y. 2000. Sources of work-family conflict: A Sino-US comparison of the effects of work and family demands. Academy of Management Journal, 43: 113-123.

Yang, Z., Zhang, H., Kwan, H. K., \& Chen, S. 2018. Crossover effects of servant leadership and job social support on employee spouses: The mediating role of employee organization-based self-esteem. Journal of Business Ethics, 147(3): 595-604.

Ye, Y., Zhu, H., Chen, Y., Kwan, H. K., \& Lyu, Y. 2021. Family ostracism and proactive customer service performance: An explanation from conservation of resources theory. Asia Pacific Journal of Management, 38(2): 645-667. 
Zhang, H., Kwan, H. K., Everett, A. M., \& Jian, Z. 2012. Servant leadership, organizational identification, and work-to-family enrichment: The moderating role of work climate for sharing family concerns. Human Resource Management, 51(5): 747-768.

Zhang, X., Liao, H., Li, N., \& Colbert, A. E. 2020. Playing it safe for my family: Exploring the dual effects of family motivation on employee productivity and creativity. Academy of Management Journal, 63(6): 1923-1950.

Publisher's note Springer Nature remains neutral with regard to jurisdictional claims in published maps and institutional affiliations.

Haixiao Chen is a $\mathrm{PhD}$ candidate of human resource management at Shanghai University of Finance and Economics. His research interests include mentoring, leadership, deviant behaviors, and work-family interfaces. His work has been published in journals such as Human Resource Management, The International Journal of Human Resource Management, and Journal of Organizational Behavior.

Ho Kwong Kwan ( $\mathrm{PhD}$, Drexel University) is an associate professor of management at China Europe International Business School (CEIBS). His research interests include mentoring, leadership, deviant behavior, and work-family interfaces. His work has been published in such journals as Academy of Management Journal, Journal of Applied Psychology, Journal of Management, Journal of Management Studies, Organizational Behavior and Human Decision Processes, Personnel Psychology, Asia Pacific Journal of Human Resources, Cornell Hospitality Quarterly, Entrepreneurship Theory and Practice, Family Business Review, Human Relations, Human Resource Management, International Journal of Hospitality Management, International Journal of Human Resource Management, Journal of Business Ethics, Journal of Business Research, Journal of Management and Organization, Journal of Managerial Psychology, Journal of Occupational and Organizational Psychology, Journal of Organizational Behavior, Journal of Vocational Behavior, Leadership Quarterly, and Service Industries Journal, as well as seven prior articles in Asia Pacific Journal of Management.

Wei-ling Ye ( $\mathrm{PhD}$, Shanghai University of Finance and Economics) is an associate professor of marketing at Shanghai University of Finance and Economics. Her research interests include consumer sentiment and decision making, advertising effectiveness, and sales force management. Her work has been published in academic journals such as Frontiers in Psychology, European Journal of Marketing, Journal of Product \& Brand Management, and Journal of Asian Journal of Social Psychology. 